\title{
ARTIFICIAL RESPIRATION IN SEVERE ABDOMINAL DISEASE*
}

\author{
BY \\ S. ALVAR SWENSSON \\ From the Department of Surgery and the Department of Anaesthesiology, Kronprinsessan Lovisas Barnsjukhus, \\ Stockholm
}

Our experience with controlled ventilation for children with acute respiratory failure of different aetiology has shown positively that with the use of the Engström respirator good results can be obtained. The following six cases represent a type of respiratory insufficiency in which there may be only minimal lung involvement.

\section{Case Reports}

Case 1. A 13-year-old boy was operated on for suspected appendicitis. Operative diagnosis was lymphadenitis. The immediate course was uncomplicated. However, three weeks later the whole family had acute gastro-enteritis. They recovered quickly, but the patient vomited for three days and was admitted to hospital in a poor condition, in deep shock, dehydrated, with a swollen abdomen. His breathing was shallow with a frequency of $40 \mathrm{breaths} / \mathrm{min}$. or more. Radiographs showed obstructive ileus with massive distended bowels (Figs. 1 and 2).

$\mathrm{He}$ was given parenteral fluids and electrolytes preoperatively, but was still a poor operative risk. However, his circulation improved a few minutes after anaesthesia was induced with the respirator.

Diagnosis was strangulation and gangrene of the lower ileum due to adhesion. The intestines were so dilated and distended that it was impossible to perform an intestinal resection. The bowel was brought to the surface of the abdomen.

After the operation he seemed well enough to be returned to his room, but on the way he suddenly became moribund, owing to respiratory insufficiency; however, on being connected to the respirator again he became conscious and circulation was restored. $\mathrm{He}$ rested completely and seemed comfortable with the respirator.

He was on respirator treatment for six days and during this time it was evident from repeated tests that the patient was unable to breathe adequately by himself. In addition, he required large amounts of fluid, electrolytes and blood because of diffuse bleeding from the intestine. The ileostomy was closed after one week, and he recovered after five weeks. During the whole course there were no lung complications of importance (Fig. 3).

* A paper read at a meeting of the British Association of Paediatric Surgeons in Stockholm, September 1961.
Comment. This patient had to overcome many negative factors working against him, among which was the abdominal-diaphragmatic guarding against pain and tenderness due to the strangulated bowel which interfered with the respiratory excursions. In addition, the dilated bowels and exudate forced the diaphragm upwards, thereby limiting the respiratory movements also. The raised respiratory work increased his metabolism which then caused an even greater demand on the respiration, and thus a vicious cycle had begun with the patient always one step behind. Crowning these difficulties were the metabolic disturbances due to the disease process itself. The patient had to compensate for this increased metabolism and for the metabolic acidosis. He did not have the energy to cope with the ventilatory work, and when he was first seen he was extremely fatigued and his condition was grave. In a short period of time he was unable to cope with his respiratory needs.

With adequate respirator treatment it was possible to operate safely, and to give adequate parenteral and other therapy.

As the respirator was applied early enough to prevent irreversible hypoxic damage the circulation improved almost immediately. The patient was followed with the respirator through each stage of compensation until almost basal conditions were reached.

After the respirator was removed the abdominal radiological findings appeared to be worse than at the time of the crisis, despite the fact that he was clinically improved and could easily breathe by himself, indicating that during the treatment the more important negative factors were overcome (Fig. 4). During this time he recovered his strength and breathed adequately despite the greatly raised diaphragm.

The question may arise as to what role the raised diaphragm played, since in the recovery stage it appeared even higher than in the acute stage. The answer is that the 'guarding', which in the acute stage cemented the diaphragm and abdominal muscles and thorax into a rigid tight cage, had melted away, leaving the patient with a flexible though enlarged abdomen, so that diaphragmatic respiratory excursions could take place.

Special laboratory tests are of little value at present, since the changes during spontaneous respiration rapidly affect the blood chemistry, so that the results of a test taken some minutes or hours previously may be of no signi- 


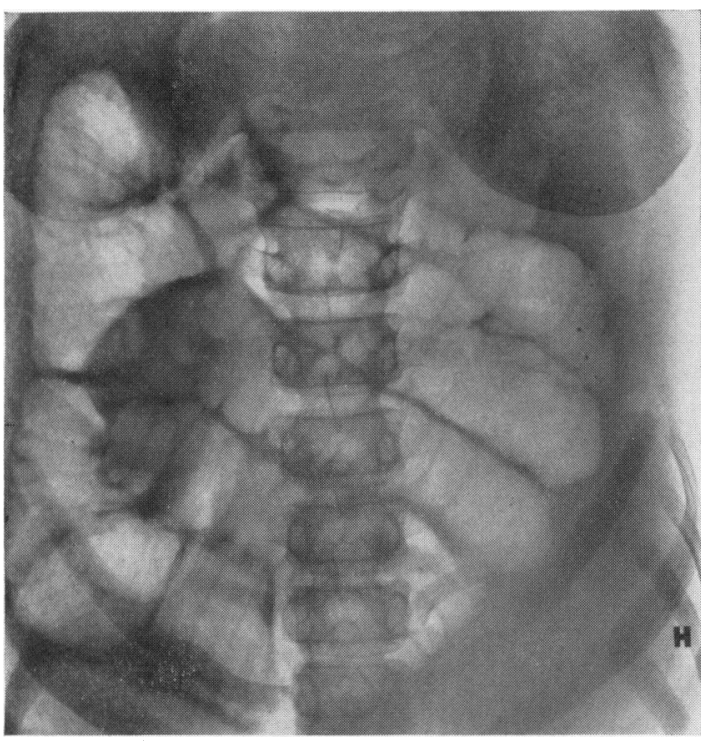

FIG. 1.-Obstructive ileus with massive distended bowels

ficance in critically ill cases. The fact that the patient is able to compensate for some time conceals his dangerous condition and gives a false assurance until

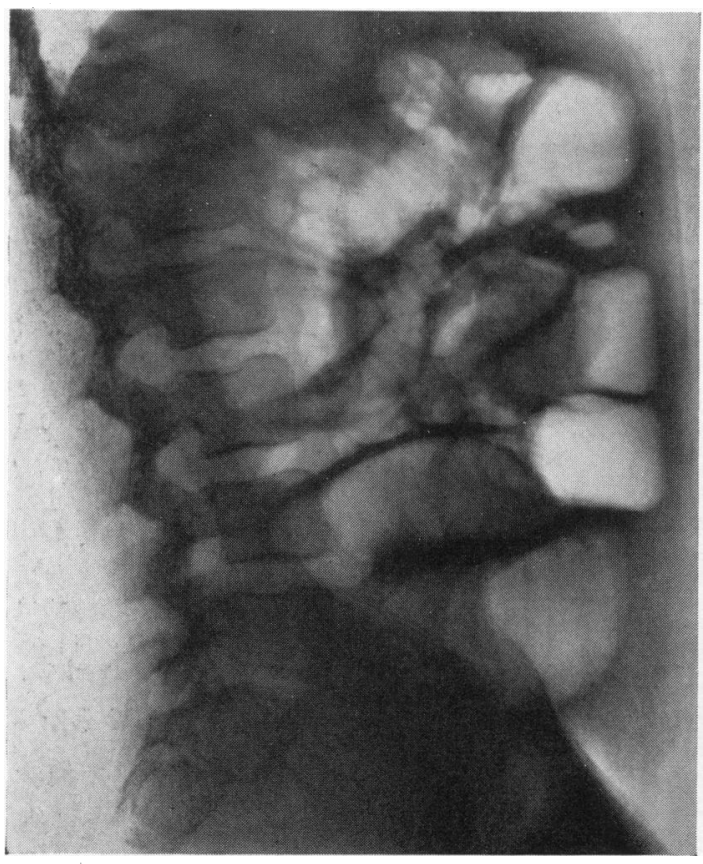

FIG. 2.-Obstructive ileus with massive distended bowels

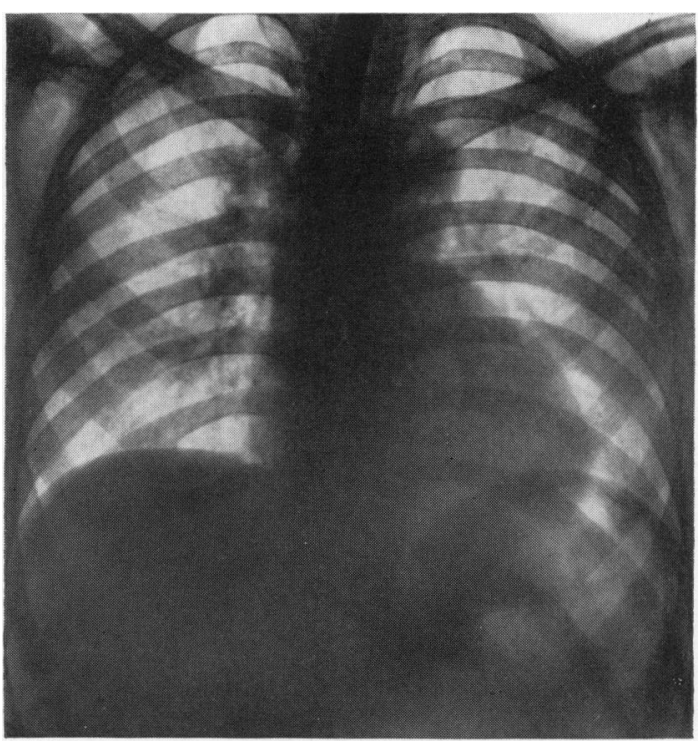

FIG. 3.-Chest radiograph shows minimal involvement in the lower left lung field.

suddenly he no longer has the energy to breathe adequately, and hypoxia occurs, followed by rapid deterioration and death.

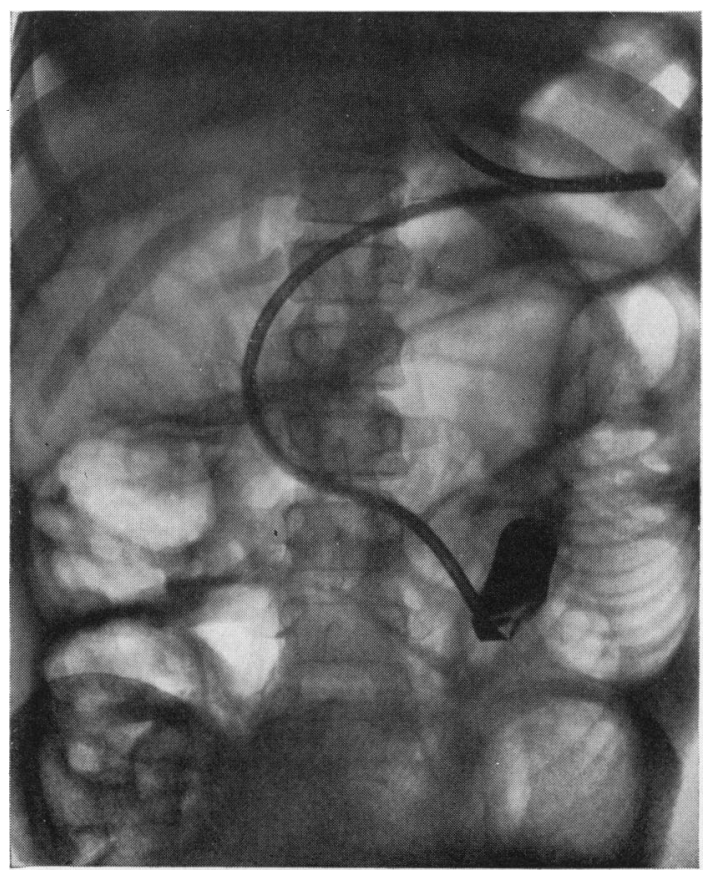

FIG. 4.-After one week without the respirator the abdominal radiological findings appeared to be worse than at the time of the crisis. 
When respirator treatment is started the so-called apnoea-duration test, which consists of disconnecting the patient from the respirator and measuring the time taken for him to start spontaneous respiration, is of value in controlling his condition. $\mathrm{He}$ is considered to be ventilated adequately when the first spontaneous respiratory movement is observed within 15 seconds of disconnecting him from the respirator. This clinical test functions only if the respiratory centre is intact, so that if possible depressant drugs should not be administered.

Case 2. A 7-year-old boy had appendicitis. There was no immediate postoperative complication.

Four months later he was operated on because of strangulative ileus with return of the circulation in the involved part of the lower ileum. The postoperative course was complicated by a fever with a temperature of $104^{\circ} \mathrm{F}$. $\left(40^{\circ} \mathrm{C}\right.$. $)$, thought to be due to a reaction to vaccination against smallpox $\mathbf{1 0}$ days earlier. His abdomen was greatly enlarged and tense. $\mathrm{He}$ was drained with a Cantor's tube and, following parenteral substitution, his fluid and electrolyte balance seemed to be satisfactory. However, clinically his condition worsened until six days later he became an emergency and was relaparotomized. New adhesions caused strangulation again, this time in the upper small bowel. Again circulation returned to the affected bowel, but the intestines were enormously enlarged (Figs. 5 and 6).

At the time of this operation he was a poor risk with difficult gasping breathing. On receiving the anaesthetic with the respirator he improved, and respirator treatment was continued postoperatively for three days. His condition improved in a short time, considering the circumstances, and his bowels moved after these three days.

At this time a jejunal fistula appeared, and during the next three weeks he was fed through a tube in the intestine. The fistula was closed with resection of the intestine and he returned home two weeks later in good condition.

Comment. This complicated course culminated at the time of the second strangulation with maximal diaphragmatic abdominal guarding which seriously hindered respiration. With respirator-controlled breathing adequate ventilation was maintained for three important days, during which time the boy was able to rest.

Case 3. A 6-year-old girl was struck by a car, causing multiple ruptures of the liver extending from the hilus with extensive intra-abdominal bleeding. The ruptures were repaired and the bleeding controlled. She responded well to these measures. The main bile-ducts and blood vessels seemed to be intact. Drainage was maintained and she felt well during the first few postoperative days.

After a week she began to complain of intermittent abdominal pain and vomited small amounts of bile. The abdomen was enlarged and tense, especially on the right side. Among other symptoms indicating a worsening of her condition was an increasing jaundice and a serum bilirubin of $12 \mathrm{mg} . / 100 \mathrm{ml}$.

In addition, her breathing became laborious due to

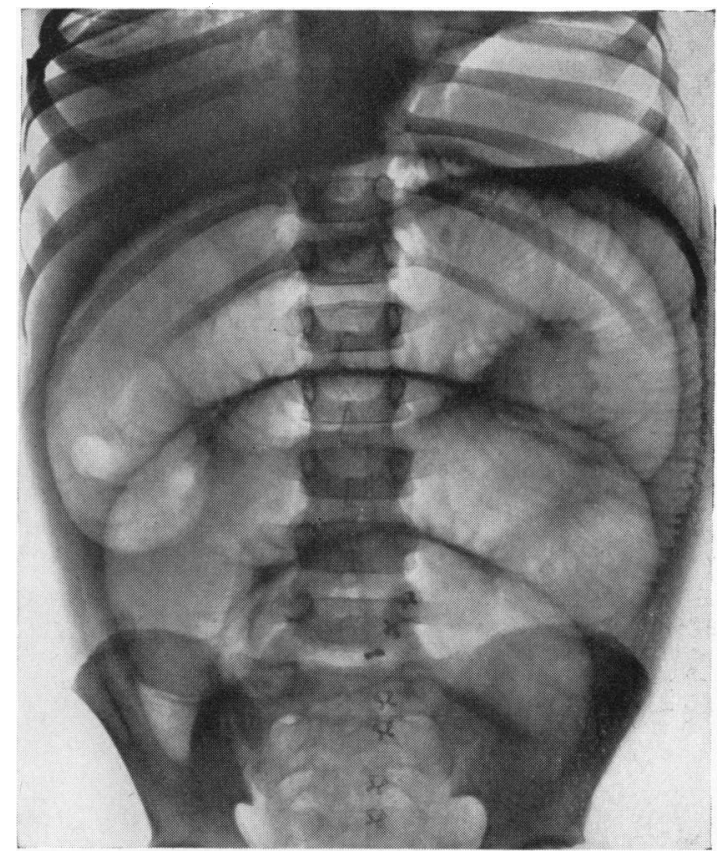

FIG. 5.-The intestines are enormously enlarged.

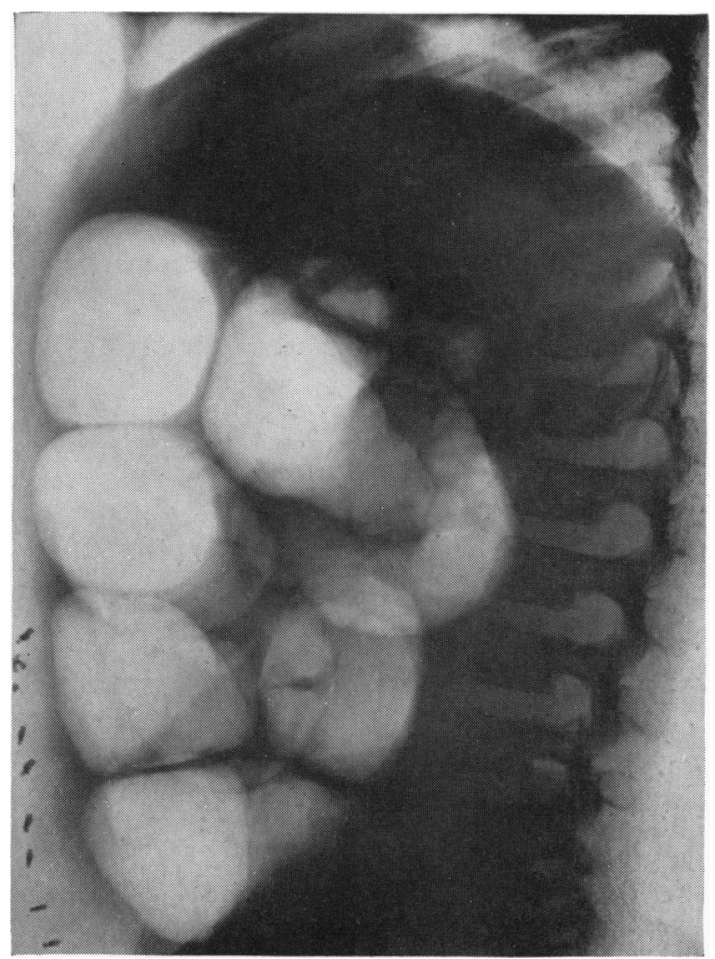

FIG. 6.-The intestines are enormously enlarged. 


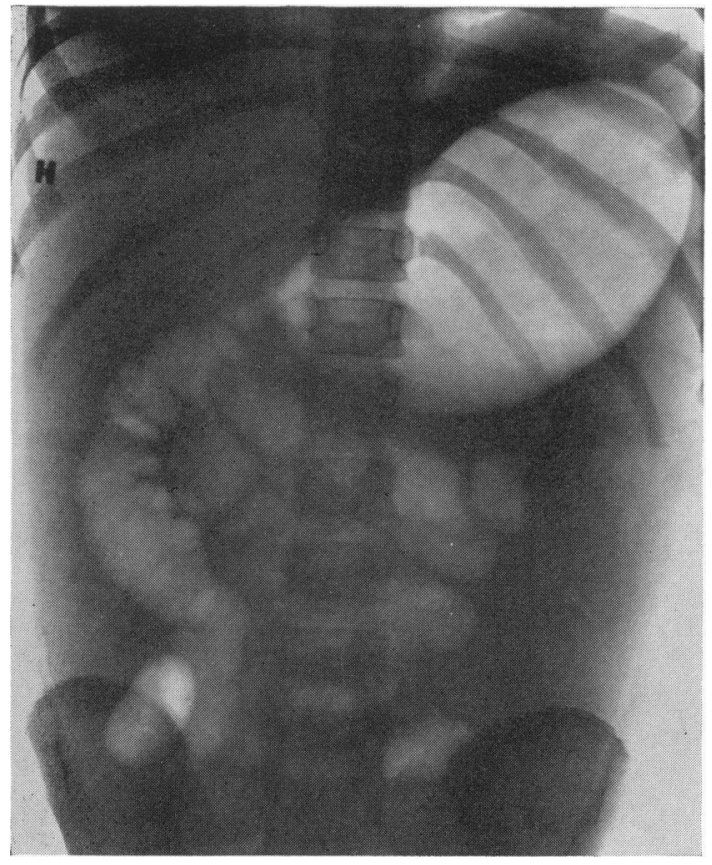

FIG. 7.-Abdominal radiograph showing a not too dramatic picture of ileus of unknown origin without gas in the colon and intraabdominal fluid.

the fact that the diaphragm was fixed in position owing to pain and abdominal irritation, and this interfered with normal breathing. Abdominal radiographs showed a not too dramatic picture of ileus of unknown origin without gas in the colon and with intra-abdominal fluid (Fig. 7). There was also a small amount of fluid in the right costophrenic angle, indicating subphrenic irritation (Fig. 8).

During the next few hours her condition became grave despite parenteral fluids and electrolytes. The abdomen was reopened and it was seen that 1.51 . of bile was causing a severe bile peritonitis.

It became quite evident that she had not the strength to carry herself through the crises, and a tracheotomy was performed and her respiration was controlled for four days. Without the respirator she had great difficulty in breathing and her peripheral circulation was bad; she was pale, cold and clammy. With respirator treatment, however, her circulation stabilized in a few minutes; her general condition also improved quickly despite the severe peritonitis. After four days of controlled ventilation her bowels moved and there were signs of recovery. Her breathing was no longer laborious but calm and normal. Her circulation remained satisfactory even without the respirator.

The following week she developed some irritation with breathing. Chest radiographs showed large left-sided pleural exudate, while the right side had cleared up (Fig. 9). There was, however, a minimal of symptoms,

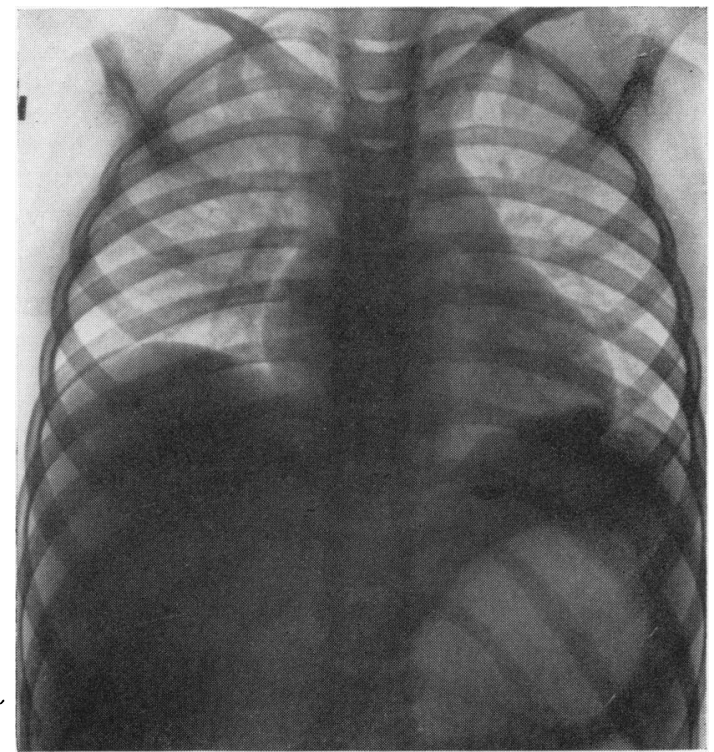

FIG 8.-There was minimal lung involvement.

indicating that the acute stage had quietened down; $350 \mathrm{ml}$. of exudate was tapped and as a result of this measure she recovered quickly without further complication.

Comment. After the first laparotomy a bile peritonitis developed, with involvement of the diaphragm, which

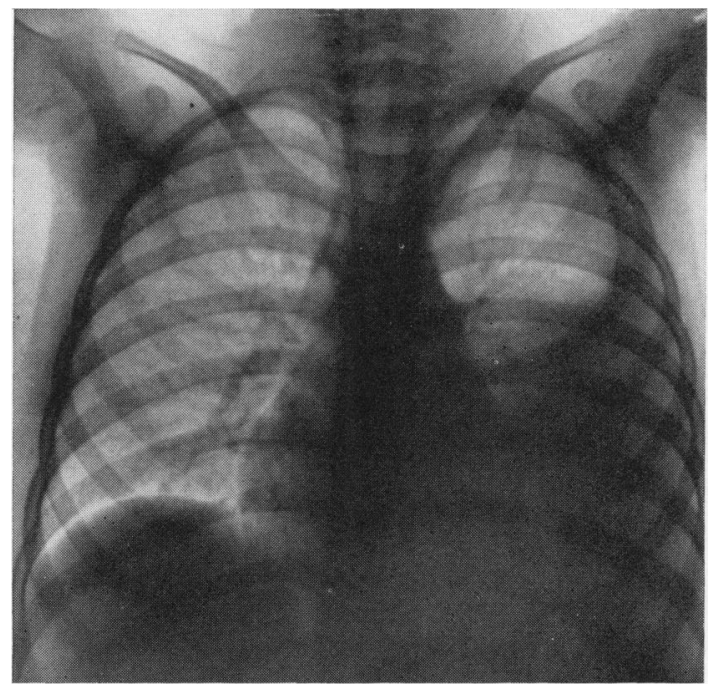

Fig. 9.-One week after discontinuing respirator treatment the chest radiograph showed marked pleural exudate on the left side, which only slightly interfered with respiration. 


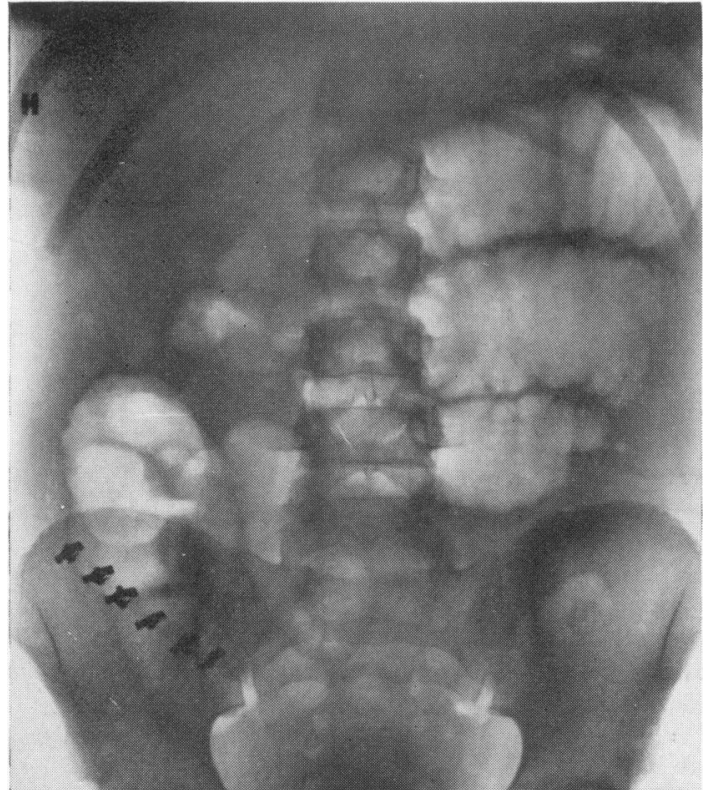

Fig. 10.-Abdominal radiograph showing the picture of paralytic ileus with an intra-abdominal abscess in the diaphragmatic region.

dangerously interfered with her breathing. With controlled ventilation for four days - all the respiratory work being taken over by the respifator and optimal gas exchange established-the patient improved rapidly and normal breathing was established again.

Case 4. A 12-year-old boy, previously healthy, became ill with abdominal pain. His parents considered

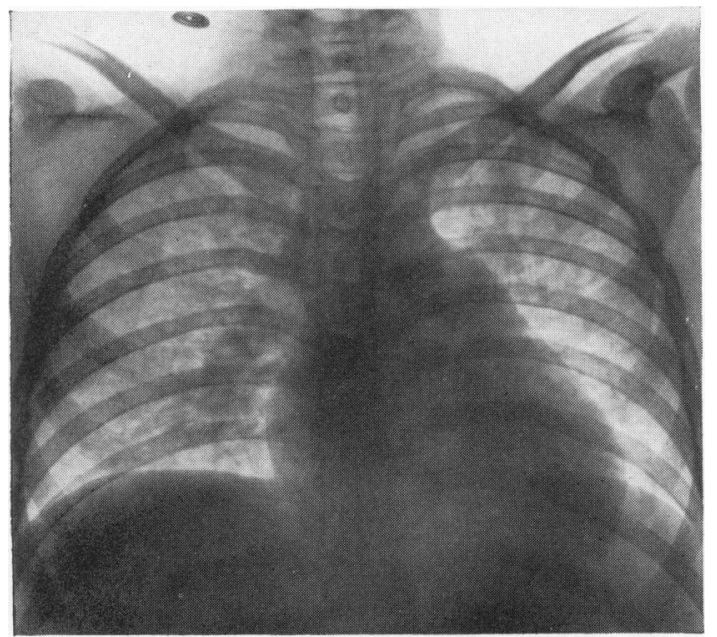

FIG. 11.-Chest radiograph shows left basal bronchopneumonia with a small amount of pleural exudate. it minor, and the child remained in bed at home for four days. He was eventually admitted to hospital, exhausted, dehydrated and with advanced peritonitis.

Following pre-operative hydration therapy, a perforated appendix was removed, and during the following four days he was maintained on parenteral therapy. Laboratory tests showed satisfactory. fluid electrolyte balance.

During the fourth postoperative day his condition became critical. The clinical signs indicated an intraabdominal abscess. No bowel movements were hitherto registered; the abdomen was tense and enlarged, and the diaphragm was fixed in position so that normal breathing was interfered with. The patient breathed shallowly with a frequency of 40 breaths/min. and with very small diaphragmatic excursions. He was weak, pale, in a cold sweat, restless and later became stuporous. His temperature had risen to $104^{\circ} \mathrm{F}$. $\left(40^{\circ} \mathrm{C}\right.$. $)$, pulse was $150 / \mathrm{min}$. and the blood pressure rose to $140 \mathrm{~mm}$. $\mathrm{Hg}$. Abdominal radiographs showed paralytic ileus with a probable mechanical interference due to intra-abdominal abscess in the diaphragmatic region (Fig. 10). In addition, there was basal bronchial pneumonia with a small amount of pleural exudate on the left side due to the subphrenic irritation (Fig. 11).

It appeared that without additional help his prognosis was grave, with a short terminal course. A tracheostomy was performed and breathing was controlled with the respirator.

He immediately followed the respirator and within a short period of time his condition improved; his circulation stabilized with a radial pulse of $100 / \mathrm{min}$. blood pressure settled at $100 \mathrm{mg}$. $\mathrm{Hg}$, colour returned, he became dry and warm, his senses cleared, he became quiet and was able to rest. The abscess was drained.

After nine days of respirator treatment he was able to breathe by himself satisfactorily, and his bowels functioned so that oral food could be taken. He remained in bed for a further three weeks and the abscess resorbed.

Comment. The intra-abdominal diseased process in the diaphragmatic region blocked the raised diaphragm causing mechanical resistance to normal respirations to a high degree. The boy became fatigued, hypoxic and shocked. He tried to compensate with some sort of frequent breathing until he became almost too tired to breathe at all.

Case 5. A 6-year-old boy had abdominal complaints and was operated on for suspected appendicitis. Operative diagnosis was mesenteric lymphadenitis.

After four days of a normal postoperative course, signs of peritonitis developed. His condition became grave despite intensive traditional therapy with antibiotics and carefully balanced fluid and electrolyte administration.

The radiological findings in the abdomen were not remarkable. Some fluid was present, indicating an intra-abdominal irritation (Fig. 12). The chest radiograph showed a small amount of exudate in the left 


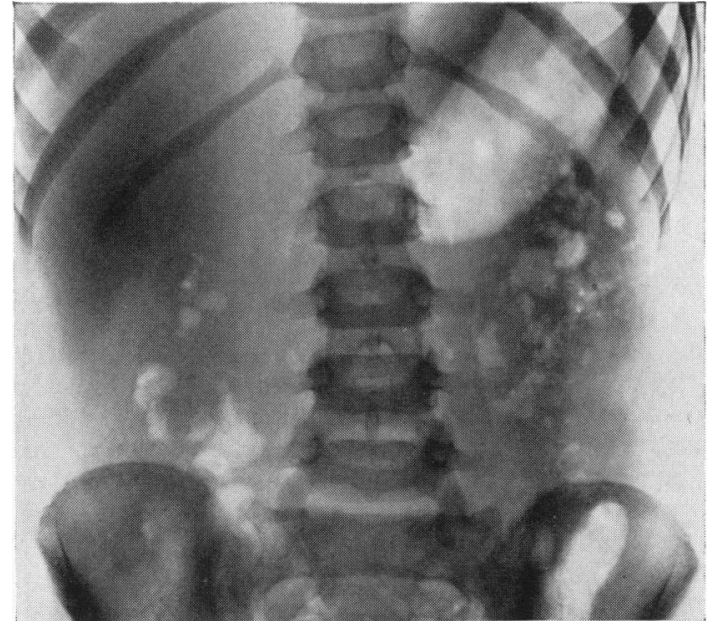

FIG. 12.-The findings in the abdominal radiograph were not remarkable. Fluid in the abdomen indicated an intra-abdominal irritation also in the diaphragmatic region.

costophrenic angle with involvement of the diaphragm (Fig. 13). Compared to the severe clinical picture the radiological findings at this stage of the course were relatively mild.

He was maintained on antibiotics and parenteral therapy for a further three days with no improvement. His breathing was laborious with small diaphragmatic excursions and it was evident that his respiratory work had increased greatly.

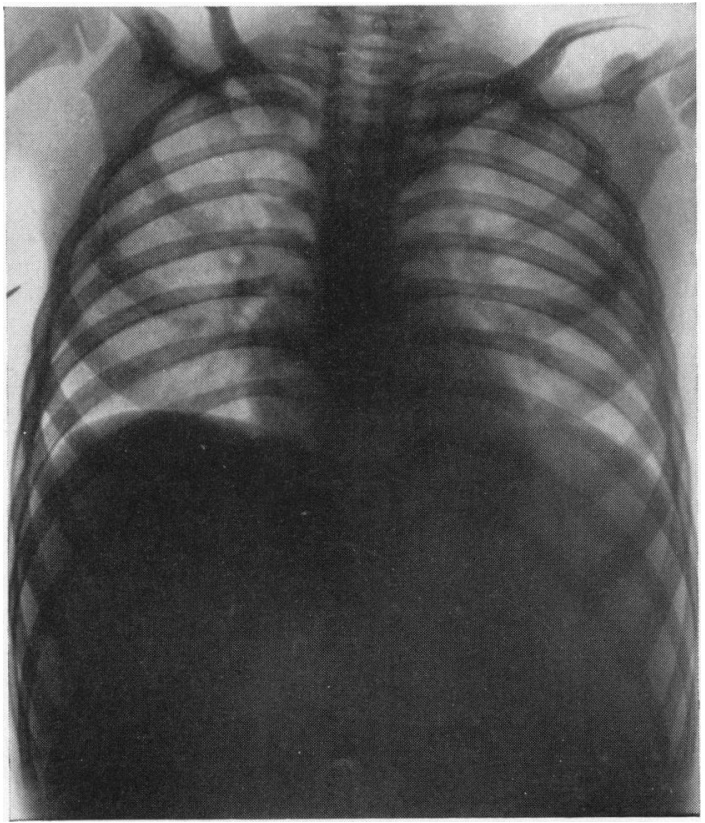

FIG. 13.-Chest radiograph showed a small amount of exudate in the left costophrenic angle.
Laparotomy was performed and revealed an abscess from which Esch. coli was cultured.

A few hours after operation he went into shock and was connected to the respirator. He immediately improved, but required respirator treatment for 48 hours before the shock disappeared. After this crisis he was able to overcome various complications during the next two months without further respirator aid (Fig. 14).

Case 6. An 11-year-old boy was admitted to hospital with peritonitis of some days' duration. He had been ill at home for four days with all the indications of acute appendicitis.

On admission he was in poor condition, in severe circulatory shock and advanced paralytic ileus. His diaphragm was raised and fixed, which greatly interfered with respiration.

He improved somewhat on being given fluid and electrolytes pre-operatively, but his condition was still critical. Anaesthesia was induced with the respirator and the patient improved so that the operation could be performed without hurrying.

The respirator treatment was continued immediately after the abdominal operation through a tracheostomy until the bowels moved after two days. The patient's condition during this treatment was good and he recovered without any complications.

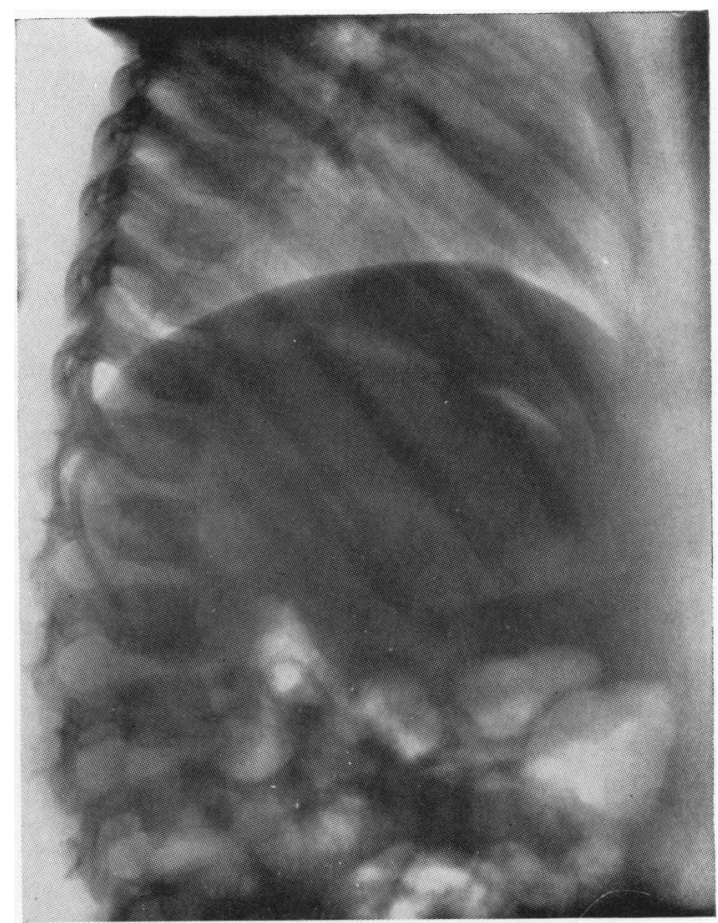

Fig. 14.-Abdominal radiograph showing abscess formation one week after discontinuing respirator treatment. The abscess appears larger here than at the time of the crisis. 
Comment. This case indicated that immediate postoperative respirator treatment was essential in order to prevent further complications and, perhaps, death.

\section{Discussion}

It is the acute irritation of the diaphragm superimposed upon the current disease pathology which is the crux of the matter and has to be clinically diagnosed and dealt with in time. The treatment is surgical and medical with aided respiration. Once the crisis is over then the subsequent course is relatively uneventful. When the patient has improved clinically the radiological findings may appear more impressive.

It is a heartening fact that there are no contraindications for either tracheostomy or adequate respirator treatment in such critically ill cases. Previously we sometimes waited until almost the last minute to start respirator treatment or discontinued the treatment rather early. Now we start earlier and maintain the treatment longer without complications.

The clinical judgement of the patient's condition is of the utmost importance. From experience we know when the patient needs help with respiration. It is then necessary to connect the patient to the respirator and control the ventilation, while there is still time, thus enabling the patient to maintain the proper cellular environment. This necessitates frequent testing of ventilatory volume during the early hours of the treatment, before basal conditions are finally reached and the ventilatory volume is adequately adjusted.

The clinical criteria in these cases were the following:

(1) Shallow gasping breathing.

(2) Alteration in respiratory frequency.

(3) Poor peripheral circulation.

(4) Immobile diaphragm with guarding which hinders breathing.

(5) Restlessness, disorientation and stupor.

This is a picture of severe shock combined with temporarily hindered respirations which can be corrected by adequately controlled ventilation.

\section{BIBLIOGRAPHY}

Abelmann, W. A., Frank, N. R., Gaensler, E. A. and Cugell, D. W. (1954). Effects of abdominal distension by ascites on lung volumes and ventilation. A.M.A. Arch. intern. Med., 93, 528.

Björk, V. O. and Engström, C. G. (1955). The treatment of ventilatory insufficiency after pulmonary resection with tracheostom and prolonged artificial respiration. $J$ thorac. Surg 30, 356. Ventilatory problems in thoracic anesthesia. A volume-cycling device for controlled respiration. ibid., 31, 117.

Erlanson, P., Lindholm, T., Lindqvist, B. and Swenson, A. (1960). Artificial respiration in severe renal failure with pulmonary insufficiency. Acta med. scand., 166, 81

Norlander, O. P., Björk, V. O., Crafoord, C., Friberg, O., Holmdahl, M., Swensson, A. and Widman, B. (1961). Controlled ventilation in medical practice. Anaesthesia, 16, 285.

Swensson A (1957). Erweiterung des Indikationsgebietes für die Anwendung künstlicher Beatmung. Langenbecks Arch. klin. Chir., 287, 274 . Chir., 287, 274 . scand., 113, 417.

(1958). Respiratorbehandling vid ileustillstånd neurologiska och neurokirurgiska sjukdomar. Nord. Med., 60, 1057. 